\title{
How are the English Stop Smoking Services responding to growth in use of electronic cigarettes?
}

\author{
Beard, E., ${ }^{1,2}$, Brose, LS., ${ }^{2,3}$ Brown, J., ${ }^{1}$ West, R., ${ }^{1,2}$ \& McEwen, A., ${ }^{1,2}$
}

${ }^{1}$ Cancer Research UK Health Behaviour Research Centre, University College London, WC1E 6BT, UK

${ }^{2}$ National Centre for Smoking Cessation and Training, London, UK

${ }^{3}$ UK Centre for Tobacco and Alcohol Studies (UKCTAS), Addictions, Institute of Psychiatry, King's College London

Journal: Patient Education and Counselling

Word count: $3,789(\max 4000)$

Correspondence to: Emma Beard, Cancer Research UK Health Behaviour Research Centre, University College London, WC1E 6BP. Email: e.beard@ucl.ac.uk. Tel: 02031083179 
Abstract (Word count: 200; Max 200)

Objectives: To assess extent of electronic cigarette use by smokers attending Stop Smoking Services, the advice given about electronic cigarettes and whether this usage is recorded.

Methods: Fifty-eight managers and 1284 practitioners completed an online survey. Questions covered use of electronic cigarettes, the advice given and whether use was recorded in client databases.

Results: Ninety per cent $(\mathrm{n}=1150)$ and $95 \%(\mathrm{n}=1215)$ of practitioners respectively, reported that their clients were using electronic cigarettes and that they had been asked about them. Seventy-one per cent $(n=41)$ of managers reported that they had a policy on the advice to be given; of whom $85 \%(n=35)$ said that practitioners should say that products were unlicensed. Fifty-five per cent $(n=707)$ of practitioners reported giving such advice and $11 \%(\mathrm{n}=138)$ said they warned smokers about their safety. Only $9 \%(n=119)$ reported that they recorded clients' use.

Conclusion: Although use of electronic cigarettes by smokers in Stop Smoking Services is common, few provisions are in place to record their use. Practitioners mostly advise that products are not licensed.

Practical implications:There is a need to consider additional training for practitioners on use of e-cigarettes and harm reduction generally to ensure that advice is consistent and evidencebased.

Keywords: Electronic cigarettes, stop smoking services, practitioners, smoking 


\section{Introduction}

The number of countries around the world offering some form of Stop Smoking Service to smokers who wish to quit is accumulating steadily, although these often differ extensively in structure and outreach [1]. Perhaps one of the most comprehensive is the United Kingdom Stop Smoking Services established in 1999, which have been instrumental in reducing smoking rates [2] and have served as a model for other countries. These services are under the direction of local authorities, with each configuring itself on the basis of national guidelines. The services aim to provide evidence-based behavioural support and access to smoking cessation medication $[3,4]$.

With the release of the National Institute of Health and Care Excellence guidance on tobacco harm reduction in June 2013, the English Stop Smoking Services may be extended to offer support and guidance to smokers who are unable or unwilling to stop smoking [5]. The guidance covers two main forms of harm reduction - smoking reduction and temporary abstinence - which have both been shown to increase the propensity of smokers to stop, particularly if supported by licenced nicotine containing products [6-8]. Although this advice may take many forms, one recommendation is that guidance on harm reduction is incorporated into the brief advice given by health-care professionals prior to service attendance. This will reduce disruption to the current services and ensure the message is still that of complete abstinence [9]. However, smokers attempting harm reduction should be encourage to attend the services when they feel ready to quit smoking and given support to stop abruptly (Note: although clinical trials have found that gradual cessation has similar efficacy as abrupt cessation, it appears to be less effective in the real world [see 10-12]).

The National Institute of Clinical and Care Excellence guidance also acknowledged the potential contribution of electronic cigarettes (e-cigarettes) to tobacco harm reduction, but 
would only advocate this approach if they became licenced medicines in the UK. Studies have shown that these devices are becoming increasingly popular, and that they may help users to reduce or quit smoking [13-20]. They also deliver clinically significant levels of nicotine into the blood, albeit, at least for some smokers, at a much lower level than traditional tobacco products [21-23]. Potentially harmful constituents have been identified in some cartridges [24,25]; though levels are much lower than those found in cigarettes [26].

However, a major limitation with many of these studies is that they were based on surveys which recruited smokers from e-cigarette forums who are likely to hold more favourable attitudes towards such products. This is evident in the study by Dawkins et al [23], where the authors reported that $74 \%$ of their sample had not smoked for several weeks since using ecigarettes. This far exceeds what would be expected for currently available efficacious treatments [27]. Much of the data thus far on safety and nicotine intake is also based on clinical trials, thus results may not play out in the real world where smokers will not generally be provided with e-cigarettes free of charge.

In June 2013, the Medicines and Healthcare products Regulatory Agency finalised their consultation on e-cigarettes and reached the decision that they should be regulated as medicines in the UK by 2016, in the belief that licensing would improve their safety and effectiveness [28]. This has put the UK at the forefront of the debate on e-cigarettes, with many other countries deliberating over their use or banning/imposing heavy restrictions, including Australia, Brazil, Lebanon, France, US and Singapore. Reasons for this hostility include the belief that they contain harmful substances, that they may encourage higher consumption of nicotine and that they will act as a gateway to smoking.

With the release of guidelines on harm reduction, and these regulatory changes to e-cigarettes, there is a need to determine the role that Stop Smoking Services will play. A first step, and 
the aim of this paper, is to ascertain the procedures stop smoking practitioners and managers have in place to record and advise smokers about the use of electronic cigarettes and to assess their beliefs about the prevalence and reasons for e-cigarette use among their clients.

It is important to discover whether Stop Smoking Services have provisions in place to record e-cigarette use, since careful monitoring will allow for the analysis of the impact of ecigarettes on quit rates over time and other significant clinical outcomes. It might be hypothesised that since they are not currently licensed, and therefore not available on prescription, that few if any monitoring procedures will be implemented. It is similarly important to determine the advice given by Stop Smoking Practitioners to ensure that the Stop Smoking Services are maintaining an evidence-based approach; since although there is strong endorsement for evidence-based practice in health-care fields, its use is often lacking [29-32].

One reason for this is that health-care professionals' personal beliefs often conflict with the evidence base and are more likely to influence practice [33-35]. For example, previous research shows that health-care professionals hold erroneous views about nicotine containing products and harm reduction generally, and that these beliefs are associated with the advice offered to smokers [36,37]. Thus if similar views are established about e-cigarettes it is plausible that Stop Smoking Practitioners may advise against their use. This situation may change in the UK in light of the recent guidance and recommendations by National Institute of Clinical and Care Excellence and the Medicines and Healthcare products Regulatory Agency, and with training on e-cigarettes and harm reduction offered to Stop Smoking Practitioners by organisations such as the National Centre for Smoking Cessation and Training.

Finally, it is of interest to assess their beliefs about how many clients are using e-cigarettes and the reasons for their use, in order to inform future polices and the training offered to Stop 
Smoking Practitioners. Previous research suggests that smokers use e-cigarettes as they are less toxic than tobacco, to quit smoking or avoid relapsing, to deal with cravings for tobacco, during periods of temporary abstinence, for smoking reduction, and because they are cheaper than cigarettes $[14,15]$. If a substantial proportion of e-cigarette users are attempting harm reduction then the prevalence of use in Stop Smoking Services may be low, on the basis that smokers who use nicotine containing products for harm reduction often do not approach health-care professionals and hold hostile beliefs about the services offered to smokers $[38,39]$.

The specific questions addressed by the current study are as follows:

1. Do stop smoking services have procedures in place to record clients' cigarette use?

2. What advice do stop smoking practitioners give their clients about e-cigarettes and is this consistent with the recommendations given by managers of stop smoking services?

3. How many clients have asked questions about e-cigarettes, tried them, or report regularly using them?

4. What reasons do smokers give stop smoking practitioners for using of e-cigarettes?

\section{Method}

\section{Procedure}

An email was sent to all Stop Smoking Managers in England on behalf of the researchers by the National Centre for Smoking Cessation and Training. All managers were requested to take part and to forward the link to their staff. An email was also sent to all Stop Smoking Practitioners on the National Centre for Smoking Cessation and Training database and to all those that completed the 2011 survey but were not on the training database. Emails were 
personalised where possible i.e. addressed practitioners and managers by name. Reminders were sent 1 and 2 weeks following the initial request. The online survey was open between the $4^{\text {th }}$ of December 2012 and $4^{\text {th }}$ of January 2013. As an incentive for participation, all those who completed the survey were entered into a prize draw for a place and accommodation at the 2013 UK National Smoking Cessation Conference worth $£ 450$.

\section{Measures}

The manager and practitioner survey comprised of 44 and 59 questions respectively. This paper reports on the subset of questions on e-cigarettes. These questions were developed by a group of researchers working in the area of tobacco harm reduction and e-cigarette use. Question design was informed by prior research, with the intention being to keep questions as clear and concise as possible, and to provide response categorises which covered the most common answers but allowed open-ended responses [40]. Standard ethical guidelines were followed: participants could withdraw at any time, all data was anonymised and the burden of study participation minimized by keeping the questionnaire as brief as possible.

Stop Smoking Managers were asked three questions about e-cigarettes: 1) Does your service have a system in place to record use of electronic cigarettes (e-cigarettes)? [Yes, No]; 2) Does your service have a recommendation of what advice practitioners should give on e-cigarettes? [Yes, No]; 3) If yes, what is the recommended advice on e-cigarettes? [Free text box of 500 characters].

Practitioners were asked six questions about electronic cigarettes: 1) What proportion of the clients you have seen this year (2012) have asked you questions about electronic cigarettes (ecigarettes)? [None, Less than a quarter, From a quarter to a half, From a half to three quarters, 
More than three quarters]; 2) What proportion of the clients you have seen this year says they have ever used e-cigarettes? [None, Less than a quarter, From a quarter to a half, From a half to three quarters, More than three quarters]; 3) What proportion of the clients you have seen this year report regularly using e-cigarettes? [None, Less than a quarter, From a quarter to a half, From a half to three quarters, More than three quarters]; 4) Of your clients who have used e-cigarettes or are currently using them what have they used them for? [To try to quit, When they were unable to smoke, To help them cut down the number of cigarettes they are smoking, As an alternative to smoking, To get rid of the smell of stale smoke, To protect their health, To protect the health of those around them; To see what they were like, Other (please state)]; 5) What advice do you give about e-cigarettes? [Free text box of 500 characters]; 6) Does your service have a system in place to record use of e-cigarettes? [Yes, No].

\section{Analysis}

Prior to the analysis, open-ended questions were coded into categorises using a thematic text analysis [41], derived from the procedures used by Hruschka et al [42] on HIV behavioural research. This involved three stages: 1) segmentation of text, 2) casebook creation, and 3) coding. The lead coder coded the text and then sent a sample to the second coder, with inconsistencies discussed and clarifications to the codebook made in response. The process continued until a Cohen Kappa of 0.8 was established. In total $50 \%$ of the text was coded by both coders. Differences between managers and practitioners who completed and did not complete the survey were assessed with chi-square and t-test analyses.

\section{Results}


One hundred and fifty-five managers were contacted, of which $82.6 \% \%(n=128)$ agreed to participate in the online survey. Of these, 70 were excluded as they terminated the survey early and did not reach the questions on e-cigarettes. This resulted in a final sample of 58 managers (37.4\% response rate). Seventy-eight per cent $(n=45)$ of managers were female. The majority were employed by a Primary Care Trust or Hospital Trust $(39.7 \%, \mathrm{n}=23)$ and on average had managed a Stop Smoking Service for $6.8(\mathrm{SD} \pm 3.78)$ years. There was no evidence that those who completed the survey differed to those who dropped out in terms of gender $\left(\mathrm{X}^{2}=0.46, \mathrm{df}=1, p=0.500\right)$ or whether they were employed by a Primary Care Trust/Hospital or other organisation $\left(\mathrm{X}^{2}=0.94, \mathrm{df}=1, p=0.332\right)$. However, those who completed the survey had worked for an average of 1.5 years longer $(\mathrm{t}=-2.12, \mathrm{df}=96, p=0.37)$.

In total, 2,420 responses were recorded for the practitioners' survey. A response rate could not be calculated because currently it is not known how many practitioners work in the English Stop Smoking Services, or how many were forwarded and received the invitation. Of these, $249(10.3 \%)$ were excluded as the respondents reported that they did not see smokers on behalf of English Stop Smoking Services and 887 (36.7\%) were excluded as they did not reach the questions on e-cigarettes. This resulted in a final sample of 1,284 practitioners $(53.1 \%$ response rate). The majority were female $(85.8 \%, \mathrm{n}=1102)$. Practitioners had worked for a mean of $7.0(\mathrm{SD} \pm 4.37)$ years. Thirty-six per cent $(\mathrm{n}=460)$ were specialist Stop Smoking Practitioners (i.e. a practitioner whose main role involves providing smoking cessation support, as opposed to a community practitioner for whom smoking cessation is a small part of their job). There was no evidence that those who completed the survey differed to those who dropped out in terms of gender $\left(\mathrm{X}^{2}=0.04, \mathrm{df}=1, p=0.845\right)$ and length of time having worked for $(\mathrm{t}=-0.03, \mathrm{df}=2,084, p=0.978)$. However, they were more likely to be specialist practitioners $\left(\mathrm{X}^{2}=42.89, \mathrm{df}=1, p<0.001\right)$. 
Table 1 shows that the majority of service managers do not have a system in place to record e-cigarette use by clients, however, a substantial proportion do offer specific recommendations as to what practitioners should inform smokers about. In the majority of cases (85.4\%), this advice was along the lines that e-cigarettes are currently not approved by the Medicines and Healthcare products Regulatory Agency or National Institute of Clinical and Care Excellence and that more research is required before they can give guidance about them.

Table 2 shows that a large proportion of practitioners have been asked about e-cigarettes by their clients in the past year, with only $5.4 \%$ of practitioners having had no clients enquire about them while $11.1 \%$ were asked by more than three-quarters of their clients. A substantial number of clients also appear to be using e-cigarettes, with only $10.4 \%$ of practitioners reporting that none of their clients have tried them. In terms of regular use, $19.8 \%$ of practitioners report that $50 \%$ or more of their clients use e-cigarettes on a regular basis. The main reasons that practitioners believed their clients used e-cigarettes were to quit smoking (71.0\%), to help them cut down $(49.9 \%)$ and for periods of temporary abstinence $(28.6 \%)$ (see Table 2). In line with the findings from the managers' survey, very few practitioners reported that systems were in place to record e-cigarette use. The main advice given was that ecigarettes were not yet approved/there was a lack of research to provide guidance $(55.1 \%)$.

\section{Discussion and conclusion}

\subsection{Discussion}

The current study found that few Stop Smoking Services have systems in place to record ecigarette use, but that a large majority of service managers do provide practitioners with 
recommendations as to the advice they should give smokers about e-cigarettes. Common advice included that e-cigarettes are not currently approved or licensed and more research is required on their efficacy and safety. The actual advice that practitioners gave their clients was similar, except many also raised safety concerns. Surprisingly, the vast majority of practitioners reported that they had been asked questions about e-cigarettes and that their clients had tried or used them regularly. Use of e-cigarettes by clients for harm reduction was common.

It is perhaps unsurprising that few Stop Smoking Services have provisions in place to record the use of e-cigarettes among their clients, since these products are not licensed medications and as such are not available on prescription. However, given that a large number of smokers are now using these devices, and the Medicines and Healthcare products Regulatory Agency have called for licensing by 2016, Services should consider implementing procedures to record prevalence and extent of use among their clients. In fact, careful monitoring of ecigarette use and the association with clinical outcomes was one of the main research objectives outlined by the National Institute of Clinical and Care Excellence guidance on harm reduction. The National Centre for Smoking Cessation and Training has already incorporated e-cigarette use into their Client Record Forms [43], while the UK National Smoking Cessation Conference this year widely encouraged monitoring by health-care professionals [44]. However, the 2012/2013 'Stop Smoking Service: monitoring and guidance update' failed to acknowledge the use of e-cigarettes [45].

The advice being given to clients appeared to be largely evidence-based and followed the guidelines provided by service managers i.e. the majority of practitioners informed smokers that the products were not currently licensed for smoking cessation or harm reduction and that further research was required. However, a substantial proportion of practitioners also actively discouraged their use due to safety concerns. These concerns were generally along two lines: 
1) stories that e-cigarettes could easily combust or explode and 2) that they contained compounds which were carcinogenic. These two points are not evidence-based. A recent study showed that the compounds in e-cigarettes are 9-450 times lower than the levels found in traditional cigarettes, and are comparable to the levels found in currently licensed nicotine containing products [26] and while it is the case that there are instances of e-cigarettes exploding, this occurs at a risk level similar to that for household goods.

Finally, it is perhaps surprising that so many practitioners have come across smokers who have tried or use e-cigarettes frequently, with a substantial minority reporting that nearly all their clients use e-cigarettes on a regular basis. These products as such appear to have high customer appeal, despite other nicotine containing products being available either at a lower price or for free depending on individual circumstance. One reason for this may be that smokers find traditional nicotine containing products unsatisfying [39], since they are designed to minimize the risks of abuse and dependence [46], or that this is simply a novelty effect. West, DiMarino and McNeill [47] reported an initial increase in use of the nicotine lozenge on its introduction to the UK market. However its use has since declined in favour of other products (e.g. the Nicotine patch)[6].

Although this study offers valuable data on the current place of e-cigarettes within Stop Smoking Services, a number of limitations need to be considered. First, no objective data were available on clinical practice. It may be the case that smokers fail to convey their use of ecigarettes to practitioners, thus resulting in practitioners underestimating the frequency of use or incorrectly reporting the reasons for use. Secondly, the response rate was quite low for the Stop Smoking Managers survey, thus the sample attained may not be representative of Stop Smoking Mangers in general. One reason for this may have been the timing of recruitment which was during the winter holiday period [48], although stop smoking services are open regularly during this time. Fourthly, the effect of drop-out may have resulted in an 
unrepresentative sample. This is evidenced by the finding that mangers who completed the survey had worked for a longer period of time, while practitioners who dropped out were less likely to be specialists. It may be the case that more experienced managers have better provisions in place to record e-cigarette use, but then again newer managers may be more likely to keep abreast with current research. Finally, the current study was based on English Stop Smoking Services. It is possible that the findings will not apply to other countries that have less liberal views on harm reduction and e-cigarettes. This would be a useful area for future research.

\subsection{Practice implications}

Despite a large majority of smokers attending Stop Smoking Services being interested in and/or are using e-cigarettes, nearly $1 / 3^{\text {rd }}$ of services do not provide practitioners with advice on what they should tell smokers. Mangers should be encouraged to keep up-to-date with developments in tobacco control and ensure that their services are providing consistent noncontradictory and accurate information. This can be achieved by providing practitioners with the necessary resources to undertake regular update training. Detailed information about ecigarettes should also be incorporated into training programmes for other health-care professionals who come into contact with smokers. In fact, it is likely that pharmacists and physicians will be the first point of call for many smokers using these products.

On the basis of current research, health-care professionals should be advised to inform smokers that some e-cigarettes are likely to be licensed by 2016 as medicinal smoking cessation aids; evidence suggests they are substantially safer than traditional cigarettes but further research is required to assess their effectiveness and safety profile; and that in the 
meantime they may wish instead to use currently licensed nicotine containing products, but the choice should be theirs.

The difficulty will be ensuring adherence to these guidelines given that previous studies have shown that only $60 \%$ of the content of stop smoking manuals provided to practitioners is communicated with fidelity in practice [49]. Moreover, providing information to practitioners in countries which do not offer structured training is likely to be an arduous task [1]. Article 14 of the 2005 World Health Organisation Framework goes someway in addressing this, by requiring parties to take effective measures to promote cessation of tobacco use and adequate treatment for tobacco dependence. The basic infrastructure elements include national training standards, mandatory reporting of tobacco use in all medical notes, a national cessation strategy and access to affordable medications and specialised tobacco dependence treatment services [50].

In addition to offering training to practitioners it should be recognized that factors other than knowledge and beliefs are important in ensuring that the guidelines and recommendations put forward by on e-cigarettes are implemented. Michie et al [33] identified a number of domains and related constructs which should be considered during the process of developing interventions to increase evidence-based practice. From this it could be argued that practitioners should not only receive training and information on the guidance, but should be encouraged to implement it, provided with an environment which is suitable for implementation, have access to the necessary tools, should receive prompts to remind them about the guidance, and reinforcement and praise for implementation. It should also be ensured that there is commitment from managerial levels and that any implementation does not conflict with current goals or create cognitive overload. Clearly this will be a difficult process in a climate of budget cuts, an ultimate goal to create a smoke-free society, and lack 
of time and resources. Thus it is important to consider carefully how and to what extent these guidelines are adopted by Stop Smoking Services.

\subsection{Conclusion}

A substantial number of smokers who attend Stop Smoking Services are now enquiring about e-cigarettes or report using them regularly for both smoking cessation and harm reduction. Few services have provisions in place to record use; nonetheless, a large proportion of Stop Smoking Practitioners offer advice and guidance on their use. In the majority of cases this advice is evidence-based and follows the recommendations of Stop Smoking Service Managers. However, there is some variability in the advice given, with a substantial minority of practitioners actively discouraging smokers from using the devices due to unsubstantiated safety concerns.

Acknowledgements

This study was funded by the National Centre for Smoking Cessation and Training (NCSCT). A place at the UK National Smoking Cessation Conference (UKNSCC) was offered by the UKNSCC organizing committee as an incentive for participation.

\section{Conflicts of interest}

EB and JB have received unrestricted funding from Pfizer. RW and AMcE have undertaken research and consultancy for companies that develop and manufacture smoking cessation medications. RW and AMcE have a share of a patent for a novel nicotine delivery device. 
LB's post at the time of the data collection was funded by the National Centre for Smoking Cessation and Training and EB's posts are funded by the NCSCT.

\section{References}

[1] Piné-Abata H, McNeill A, Murray R, Bitton A, Rigotti N, Raw M. A survey of tobacco dependence treatment services in 121 countries. Addiction 2013;108:1476-84

[2] Department of Health. Smoking kills: A white paper on tobacco. London, UK: Department of Health, 1998

[3] Department of Health. Local stop smoking services: key updates to the 2011/12 service delivery and monitoring guidance for 2012/13. Department of Health, 2013.

[4] Raw M, McNeill A, West R. Smoking cessation guidelines for health professionals-a guide to effective smoking cessation interventions for the health care system. Thorax1998; 53:S1-19

[5] National Institute of Clinical and Care Excellence. Tobacco - harm reduction. Accessed: 2013-07-15. (Archived by WebCite ${ }^{\circledR}$ at http://www.webcitation.org/6I8H2UsRX), 2013

[6] Beard E, Aveyard P, Michie S, McNeill A, West R. Does use of nicotine replacement therapy while continuing to smoke undermine cessation?: A systematic review. J Smok Cess 2013; 8(1): 45-56.

[7] Beard E, Aveyard P, Brown J, West R. Assessing the association between the use of NRT for smoking reduction and attempts to quit smoking using propensity score matching. J Drug Alcohol Depend 2012; 126(3): 354-361

[8] Moore D, Aveyard P, Connock M, Wang D, Fry-Smith A, Barton P. Effectiveness and safety of Nicotine Replacement Therapy assisted reduction to stop smoking: Systematic review and meta-analysis. BMJ 2009; 338: 1024. 
[9] Local Stop Smoking Services. Key updates to the 2011/12 service delivery and monitoring guidance for 2012/13. London: Department of Health, 2012.

[10] Cheong Y, Yong HH, Borland R. Does how you quit affect success? A comparison between abrupt and gradual methods using data from the International Tobacco Control Policy Evaluation Study. Nicotine Tob Res 2007; 9(8): 801-10.

[11] West R, McEwen A, Bolling K, Owen L. Smoking cessation and smoking patterns in the general population: a 1-year follow-up. Addiction 2001; 96(6): 891-902.

[12] Lindson-Hawley N, Aveyard P, Hughes JR. Reduction versus abrupt cessation in smokers who want to quit. Cochrane Database Syst Rev 2012; 11: CD008033

[13] Ayers J, Ribisi K, Brownstein J. Tracking the rise in popularity of electronic nicotine delivery systems (electronic cigarettes) using search query surveillance. Am J Prev Med 2011; 40: 448-453.

[14] Etter JF. Electronic cigarettes: a survey of users. BMC Public Health 2010; 10: 231.

[15] Etter JF, Bullen C. Electronic cigarette: users profile, utilisation, satisfaction and perceived efficacy. Addiction 2011; 106: 2017-2028.

[16] Heavner K, Dunworth J, Bergen P, Nissen C, Phillips CV. Electronic cigarettes (ecigarettes) as potential tobacco harm reduction products: results of an online survey of ecigarette users. Tobacco Harm Reduction [Internet], working paper 011. Available from: http://www.tobaccoharmreduction.org/wpapers/011.htm, 2009

[17] McQueen A, Tower S, Sumner W. Interviews with "vapers": Implications for future research with electronic cigarettes. Nicotine Tob Res 2011; 13: 860-867.

[18] Polosa R, Caponnetto P, Morjaria JB, Papale G, Campagna D, Russo C. Effect of an electronic nicotine delivery device (e-cigarette) on smoking reduction and cessation: a prospective 6 month pilot study. BMC Public Health 2011; 11: 786. 
[19] Siegel MB, Tanwar KL, Wood KS. Electronic cigarettes as a smoking-cessation tool: results from an online survey. American Journal of Preventive Medicine 2011; 40: 472-475. [20] Caponnetto P, Polosa R, Russo C, Leotta C, Campagna D. Successful smoking cessation with electronic cigarettes in smokers with a documented history of recurring relapses : a case series. J Med Case Rep 2011; 5: 585.

[21] Vansickel AR. Weaver MF, Eissenberg, T. Clinical laboratory assessment of the abuse liability of an electronic cigarette. Addiction 2012; 107(8): 1493-1500.

[22] Bullen C, McRobbie H, Thornley S, Glover M, Lin R, Laugesen M. Effect of an electronic nicotine delivery device (e cigarette) on desire to smoke and withdrawal, user preferences and nicotine delivery: randomised cross-over trial. Tob Control 2010; 19: 98-103. [23] Dawkins L, Turner J, Roberts A, Soar K. 'Vaping' profiles and preferences: an online survey of electronic cigarette users. Addiction 2013; DOI: 10.1111/add.12150.

[24] Cobb N, Byron M, Abrams D, Shields P. Novel nicotine delivery systems and public health: The rise of the "e-cigarette". Am J Public Health 2010; 100(12): 2340-2342.

[25] U.S. Food and Drug Administration. Evaluation of e-cigarettes. Available from: http://www.fda.gov/downloads/Drugs/ScienceResearch/UCM173250.pdf, 2009

[26] Goniewicz ML, Knysak J, Gawron M, Kosmider L, Sobczak A, Kurek J, Prokopowicz A, Jablonska-Czapla M, Rosik-Dulewska C, Havel C, Jacob P, Benowitz N. Levels of selected carcinogens and toxicants in vapour from electronic cigarettes. Tob Control 2013; doi:10.1136/tobaccocontrol-2012-050859.

[27] West R, Stapleton J. Clinical and public health significance of treatments to aid smoking cessation. Eur Respir Rev 2008; 17(110): 199-204.

[28] Medicines and Healthcare products Regulatory Agency. Nicotine containing products. MHRA: London. Accessed: 2013-07-15. (Archived by WebCite ${ }^{\circledR}$ at http://www.webcitation.org/6I89OvSYh), 2013 
[29] Bennett S, Tooth L, McKenna K, Rodger S, Strong J, Ziviani J, Mickan S, Gibson L. Perceptions of evidence-based practice: A survey of Australian occupational therapists. Aust Occup Ther J 2003; 50: 13-22.

[30] Meline T, Paradiso T. Evidence-based practice in schools: Evaluating research and reducing barriers. Lang Speech Hear Serv Sch 2003; 34: 273-283.

[31] Metcalfe C, Lewin R, Wisher S, Perry S, Bannigan K, Moffett JK. Barriers to implementing the evidence-based in for NHS therapies. Physiotherapy 2001; 11: 433-441.

[32] Turner P, Whitfield TWA. Physiotherapists' use of evidence-based practice: A crossnational study. Physiother Res Int 1997; 2: 17-29.

[33] Michie S, Johnston M, Abraham C, Lawton R, Parker D, Walker A. Making psychological theory useful for implementing evidence based practice: a consensus approach. Qual Saf Health Care 2005; 14: 26-33.

[34] Bonetti D, Johnston M, Pitts N, Deery C, Ricketts I, Bahrami M, Ramsay C, Johnston J. Can psychological models bridge the gap between clinical guidelines and clinicians' behaviour? A randomised controlled trial of an intervention to influence dentists intention to implement evidence-based practice. Br Dent J 2003; 195: 602-606.

[35] Graham I. I believe therefore I practise. The Lancet 1996; 347: 4-5.

[36] Borreli B, Novak SP. Nurses' knowledge about the risk of light cigarettes and other tobacco ‘harm reduction' strategies. Nicotine Tob Res 2007; 9: 653-661.

[37] Beard E, McDermott M, McEwen A, West R. Beliefs of stop smoking practitioners in United Kingdom on the use of nicotine replacement therapy for smoking reduction. Nicotine Tob Res 2012; 14(6): 639-647.

[38] Hammond D, Reid JL, Driezen P, Cummings KM, Borland R, Fong GT, McNeill A. 'Smokers' use of nicotine replacement therapy for reasons other than stopping smoking: findings from the ITC Four Country Survey'. Addiction 2008; 103: 1696-703. 
[39] Beard E, Vangeli E, Michie S, West R. The use of nicotine replacement therapy for smoking reduction and temporary abstinence: an interview study. Nicotine Tob Res 2012; 14(7): 849-856.

[40] Dillman DA. Mail and internet surveys: The Tailored Design Method. UK: John Wiley \& Sons. 2007.

[41] Guest G, MacQueen K, Namey E. Applied thematic analysis. Thousand Oaks, CA: Sage, 2012.

[42] Hruschka DJ, Schwartz D, St John DC, Picone-Decario E, Jenkins RA, Carey JW. Reliability in coding open-ended data: Lessons learned from HIV behavioural research. Field Methods 2004; 16(3): 307-331.

[43] NCSCT. Stop Smoking Service Client Record Form. Accessed: 2013-07-15. (Archived by WebCite ${ }^{\circledR}$ at http://www.webcitation.org/6I8A2Ckwd), 2013.

[44] UKNSCC. (2013 UK National Smoking Cessation Conference, London. Accessed: 201307-15. (Archived by WebCite ${ }^{\circledR}$ at http://www.webcitation.org/6I8ABdz8n)

[45] Department of Health. (2012). Local stop smoking services: Key updates to the 2011/2012 service delivery and monitoring guidance for 2012/2013. England: Department of Health. Retrieved from: https://www.gov.uk/government/uploads/system/ uploads/attachment_data/file/156152/9193-TSO-2900254-NHS-StopSmoking_Accessible. pdf.pdf, 2013.

[46] McNeill A, Foulds J, Bates C. Regulation of nicotine replacement therapies (NRT): a critique of current practice. Addiction 2001; 96: 1757-1768.

[47] West R, DiMarino ME, McNeill A. Impact of UK policy initiatives on use of medicines to aid smoking cessation. Tob Control 2005; 14: 166-171.

[48] Sheehan KB. E-mail response rate: A review. Journal of Computer-Mediated Communication 2006; 6(2): 0. 
[49] Lorencatto F., West R., Christopherson C, Michie S. Assessing fidelity of delivery of smoking cessation behavioural support in practice. Implementation Science 2013; 8: doi: 10.1186/1748-5908-8-40.

[50] World Health Organization (WHO). WHO Framework Convention on Tobacco Control. Available at: http://www.who.int/fctc/text_download/en/index.html (accessed 17 December 2012) (Archived by WebCite® at http://www.webcitation.org/6CyciAvgl on 17 December 2012) 2003 .

"I confirm all patient/personal identifiers have been removed or disguised so the patient/person(s) described are not identifiable and cannot be identified through the details of the story." 